\title{
Sensitivity of an apparently hurricane-like polar low to sea-surface temperature
}

Article in Quarterly Journal of the Royal Meteorological Society · February 2017

DOI: $10.1002 / \mathrm{qj} .2980$

CITATIONS

0

2 authors:

\section{Erik W. Kolstad}

Uni Research AS

22 PUBLICATIONS 388 CITATIONS

SEE PROFILE
READS

28

Thomas Bracegirdle

British Antarctic Survey

57 PUBLICATIONS $\quad \mathbf{1 , 2 5 8}$ CITATIONS

SEE PROFILE

Some of the authors of this publication are also working on these related projects: 
This is a preprint. Please download the full article from the Quarterly Journal's web site.

\title{
Sensitivity of an apparently hurricane-like polar low to sea-surface temperature
}

\author{
E. W. Kolstad ${ }^{\mathrm{a}^{*}}$ and T. J. Bracegirdle ${ }^{\mathrm{b}}$ \\ ${ }^{a}$ Uni Research Climate, Bjerknes Centre for Climate Research, Bergen, Norway \\ ${ }^{\mathrm{b}}$ British Antarctic Survey, Cambridge, UK \\ "Correspondence to: Erik W. Kolstad, Uni Research Climate, Allégaten 70, 5007 Bergen, Norway. \\ E-mail: erik.kolstad@uni.no
}

\begin{abstract}
Polar lows are intense, small-scale cyclones in the high latitudes. Typically, polar lows are initiated through baroclinic processes, but they sometimes evolve into a post-baroclinic mature stage where air-sea interaction becomes more important. In this stage some polar lows have developed hurricane-like cloud structures, and idealised axisymmetric hurricane models have indicated that air-sea interaction-fuelled pressure drops of up to $50 \mathrm{hPa}$ are theoretically possible in polar environments. Here we study a polar low that formed in an extreme marine cold air outbreak over the Barents Sea and which had cloud structures with similarities to hurricanes. Using a high-resolution weather model, we artificially modified the sea surface temperatures (SSTs) to assess if the polar low was close to developing into a true hurricane-like system, with air-sea interaction processes leading to intensification in the post-baroclinic, mature phase of its life cycle. The polar low simulations with SSTs augmented by 2-6 K produced more intense mature phases than the control experiment (with unmodified SSTs). The intensity of the polar low in the latter of these, which it must be pointed out was unrealistic with an SST increase of $6 \mathrm{~K}$, surpassed the intensity in the earlier baroclinic phase. The experiment where the SSTs were reduced by $2 \mathrm{~K}$ did not produce a much weaker polar low than the control run. Broadly speaking, our experiments suggest that in this case large and unrealistic SST increases would be needed for apparently hurricanelike polar lows to exhibit true hurricane-like behaviour, but nevertheless air-sea interaction did drive a more intense and prolonged mature phase.
\end{abstract}

1. Introduction

Polar lows are small-scale cyclones that form in marine cold air outbreaks (Kolstad and Bracegirdle, 2008) at high latitudes (Rasmussen and Turner, 2003). They typically develop when upper- and lower-level disturbances interact in unstable air masses (Businger, 1985; Ese et al., 1988; Montgomery and Farrell, 1992; Blechschmidt et al., 2009), but they sometimes enter a post-baroclinic phase where air-sea interaction and diabatic processes become more important (Nordeng, 1990; Nordeng and Rasmussen, 1992; Mailhot et al., 1996; Claud et al., 2004; Bracegirdle and Gray, 2009; Føre et al., 2012).

After satellite images revealed that some polar lows resemble hurricanes in their post-baroclinic phases (Rasmussen, 1979), several studies have shown that mechanisms central to hurricane development can theoretically lead to intensification in polar environments (Rasmussen, 1979; Emanuel and Rotunno, 1989; Craig and Gray, 1996). In particular, Emanuel and Rotunno used an idealised axisymmetric hurricane model to show that a pressure drop of up to $50 \mathrm{hPa}$ is possible through air-sea interaction processes that are the primary drivers of hurricane intensification (Emanuel and Rotunno, 1989). However, to date such 'Arctic hurricanes' have not been observed in reality. Here we study a polar low (referred to as 'the PL' henceforth) that appeared to be close to hurricane-like intensification. 
This is a preprint. Please download the full article from the Quarterly Journal's web site.

The PL has studied before by Føre et al. (2012) and Kolstad et al. (2016). The latter study, which will be referred to as KBZ from now on, made use a technique known as spectral nudging (von Storch et al., 2000) to force the model simulations to conform with the boundary data. This was shown to be crucial for reproducing a realistic development in the initial baroclinicity-driven phase. The key question addressed here is: Was the $P L$ actually close to developing into a true hurricane-like system, with air-sea interaction processes leading to intensification in the post-baroclinic, mature phase of its life cycle?

The PL was selected because its cloud structures were somewhat similar to those of hurricanes, albeit on a small spatial scale. It also remained more or less stationary over the eastern part of the Barents Sea for a relatively long period, allowing it enough time, at least theoretically, to intensify significantly through hurricane-like processes. In addition, satellite remote sensing and the previous case studies have indicated that the PL produced high surface wind speeds. Furthermore, the low-level vertical temperature gradient between SST and air temperature, a well-documented indicator of favourable conditions for polar low formation (Mansfield, 1974; Businger, 1985; Grønås and Kvamstø, 1995; Rasmussen and Turner, 2003; Kolstad, 2011), was the fifth highest over the Barents Sea in the period from 1979 to 2015, according to the ERA-Interim reanalysis (Dee et al., 2011).

Other studies using full-complexity weather models to evaluate polar lows that resemble hurricanes in structure generally report only weak intensification or maintenance during the hurricane-like phase, preceded by development attributed to other processes (Nordeng and Rasmussen, 1992; Albright et al., 1995; Føre et al., 2012). For example, Albright et al. (1995) found that hurricane force winds only occurred if SSTs were increased from $0^{\circ} \mathrm{C}$ to $8^{\circ} \mathrm{C}$ in simulations of a polar low over Hudson Bay. Idealised studies where the SST was set to about $7^{\circ} \mathrm{C}$ have shown that it is theoretically possible for a polar low to develop into a hurricane-like cyclone even with no baroclinicity in the basic state, but the development was slower than when there was baroclinicity present from the beginning (Yanase and Niino, 2005, 2007).

We extend previous idealised studies by investigating the effect of SST changes on the structure and physical mechanisms of the PL. In four sensitivity experiments, we introduce SST anomalies of $-2,+2,+4$ and $+6 \mathrm{~K}$ and switch off the nudging just before the peak intensity of the baroclinic phase, allowing the system to develop freely in the new environment. Our analysis is based on a range of diagnostics that were calculated to illustrate the differences between the sensitivity experiments.

\section{Data and Methods}

The simulations were performed with mainly the same model setup as in KBZ. Version 3.5.1 of the Weather Research and Forecasting (WRF) model (Skamarock and Klemp, 2008) was used, with the ERA-Interim reanalysis (Dee et al., 2011) on 60 model levels used as boundary and initial conditions. A domain at $3 \mathrm{~km}$ grid spacing (see Figure 1 in KBZ or Figure 2 herein for the boundaries) was nested inside an outer domain at $15 \mathrm{~km}$. The domains were square and had 331 and 146 grid points on each side, respectively. We used 41 vertical levels, with the 24 lowest levels below $700 \mathrm{hPa}$. Two-way feedback between the domains was switched on.

The main difference between the model setup used here and the one used in KBZ is that we used the MM5 similarity surface layer scheme (Beljaars, 1995), in which dissipative heating was switched on with enthalpy flux coefficients following Garratt (1994), instead of the MYNN scheme (Nakanishi and Niino, 2009) that was used by KBZ. Dissipative heating has been shown to be important for representing the large surface heat fluxes in tropical cyclones (Bister and Emanuel, 1998; Jin et al., 2007; Green and Zhang, 2013), and in our case the introduction of this parameterization yielded a stronger simulated PL in the control run here than in KBZ.

Spectral nudging (von Storch et al., 2000) was used during the initial development to force the model runs to comply with upper-level forcing: a crucial factor for polar lows (Shapiro et al., 1987; Montgomery and Farrell, 1992; Grønås and Kvamstø, 1995; Kolstad, 2011; Shimada et al., 2014). However, no nudging was applied below model level $24($ c. $700 \mathrm{hPa})$, and the strength of the nudging was increased linearly to full strength above model level 29 (c. $500 \mathrm{hPa}$ ). The nudging wavelength was $730 \mathrm{~km}$, and only winds and temperature were nudged. This means that the smaller wavelengths at lower levels were free to develop in the model, but the large-scale forcing at upper levels was retained.

The control run, referred to as CTRL, was initialised at 1200 UTC on 17 December 2002, and restart files were saved every three hours. The SST and sea ice fields were continually updated from the boundary input, using the sst_update option in WRF. The perturbed runs were started from restart files at $\mathrm{T}+36$, at which point we switched off spectral nudging. This is another difference with respect to KBZ, where nudging was switched 
This is a preprint. Please download the full article from the Quarterly Journal's web site.

on throughout the model runs. The lower boundary input was artificially modified by subtracting $2 \mathrm{~K}$ and adding 2,4 and $6 \mathrm{~K}$ to the SST fields from T+39 and onwards, in experiments referred to as SST $-2, \mathrm{SST}+2, \mathrm{SST}+4$ and $\mathrm{SST}+6$, respectively. (Note that for technical reasons, we could not update the SSTs at T +36 because they were already included in the restart files, so we updated them three hours later.) We did not allow new SST values below the freezing point when $2 \mathrm{~K}$ was subtracted. Thus we did not have to fill any ocean grid cells with sea ice. Similarly, we did not "melt" sea ice when increasing the SSTs. This gave unrealistically warm SSTs near the sea ice edge, but as the main development of the PL occurred far away from the ice edge, we do not believe that this had large impacts on our results and conclusions.

Brightness temperatures and SLP were computed with NCEP's (National Centers for Environmental Prediction) Unified Post Processor software (version 2.2), which was also used for interpolation to pressure levels. For evaluation, Advanced Very-High Resolution Radiometer (AVHRR) infrared satellite imagery and QuikSCAT (Hoffman and Leidner, 2005) scatterometer-derived wind speeds were used.

In order to compare the different simulations, we calculated a number of metrics, using the model grid points inside a circular region $r$ with a radius of $200 \mathrm{~km}$ surrounding the low centre at the surface at any given time. These metrics include the maximum wind speed, the mean vertical wind shear between 925 and $700 \mathrm{hPa}$, the mean sensible and latent heat fluxes, the mean precipitation rate over the last hour, and two other metrics that will be described in more depth.

We used a modified version of Hart's (Evans and Hart, 2003) thermal wind measure of warm core structure as:

$$
-\left.\mathrm{V}_{T}^{L} \stackrel{\text { def }}{=} \frac{\partial\left(Z_{\mathrm{MAX}}-Z_{\mathrm{MIN}}\right)}{\partial \ln p}\right|_{925 \mathrm{hPa}} ^{700 \mathrm{hPa}} .
$$

$Z_{\text {MAX }}$ and $Z_{\text {MIN }}$ are the maximum and minimum values of geopotential height, evaluated at 700 and $925 \mathrm{hPa}$ inside $r$. Warm core systems typically have positive values.

Kinetic energy was computed as the vertical mean of the following quantity at 700, 850, and $925 \mathrm{hPa}$ :

$$
K \stackrel{\text { def }}{=} \overline{\rho\left(u^{2}+v^{2}+w^{2}\right)} / 2,
$$

where $\rho$ is the density and $u, v$, and $w$ are the zonal, meridional and vertical wind components, respectively, and the bar indicates that the energy is the mean for all the grid points inside $r$.

\section{Results}

The case studies by Føre et al. (2012) and KBZ indicated that the PL intensified baroclinically, peaking in strength at about 06:00 UTC on 19 December, followed by a mature phase dominated by air-sea interaction. In Figure 1, AVHRR satellite images of the PL are shown for three distinct times, of which the first (Figure 1(a)) is about four hours before the peak in intensity. The next time shown is at 10:17 on the same day (Figure 1(b)), and by this time the low-level cloud structures had developed into a spiral-shaped pattern. By 02:04 on 20 December (Figure 1(c)), the PL had started to resemble a hurricane, with several deep convection cells, as indicated by the white regions in the picture.

In Figure 2, simulated brightness temperatures are shown for the times corresponding to the images in Figures 1(b) and 1(c). Note that the intervals for the grayscales in Figure 2 were chosen by us and are therefore not necessarily perfectly calibrated with Figure 1 . Figures 2(a)-(e) indicate that the model runs were able to reproduce the main features of the actual PL at 10:17 UTC on 19 December (T+46) shown in Figure 1(b), and the lighter shades and larger sizes of the cumulus cells in the experiments where the SSTs were increased seen in Figures 2(c)-(e) already indicate stronger convection than in CTRL (Figure 2(a)) and SST-2 (Figure 2(b)) just seven hours after the SSTs were perturbed.

Moving to 02:04 UTC on 20 December, Figure 2(f) shows that the simulated brightness temperatures at T +62 in CTRL corresponded very well with the mature PL shown in Figure 1(c) in terms of location, cloud distribution and spatial scale. Arguably, the visual similarity between the CTRL PL and the actual PL is greater than the one obtained in the control run in KBZ, where parameterization of dissipative heating was not used. The SST-2 simulation shown in Figure 2(g) did not reproduce the observed large patches of convective clouds surrounding the PL centre, indicating less vigorous convection in the model than in reality. The augmented SST simulations 
This is a preprint. Please download the full article from the Quarterly Journal's web site.

(Figures $2(\mathrm{~h})-(\mathrm{j}))$ produced gradually increasing degrees of convection, as is natural with increasing heating from below.

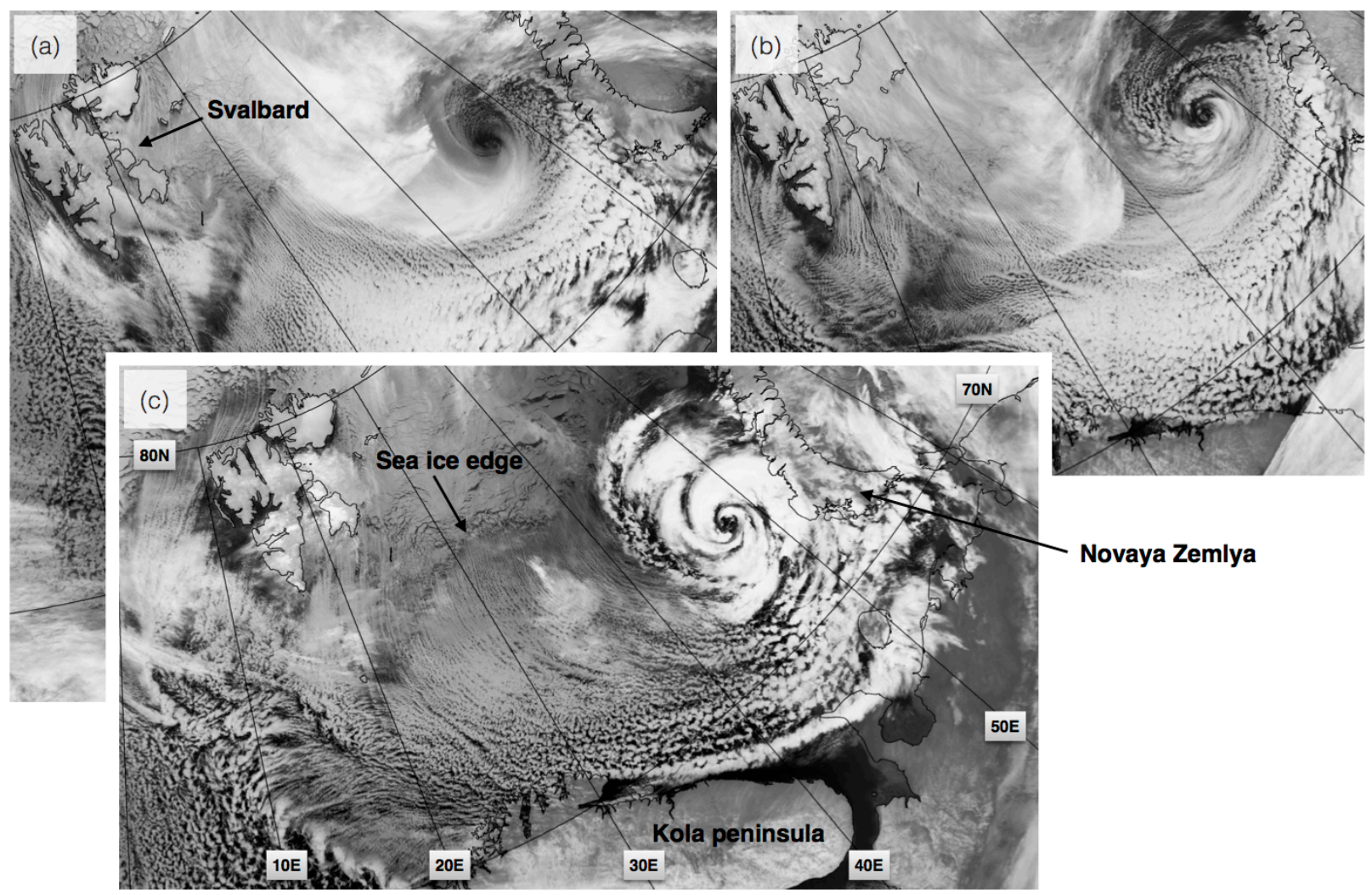

Figure 1. AVHRR images of the PL at three times: at 02:15 UTC on 19 December 2002 (a), at 10:17 UTC on the same day (b), and at 02:04 UTC on 20 December (c). The images were printed with the kind permission of the Dundee Satellite Receiving Station.
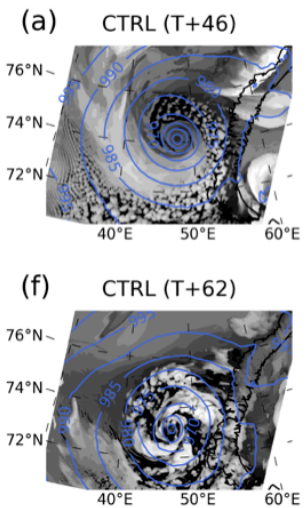
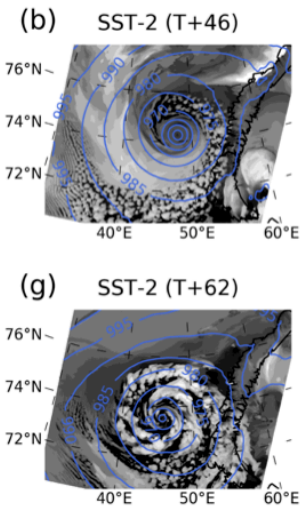
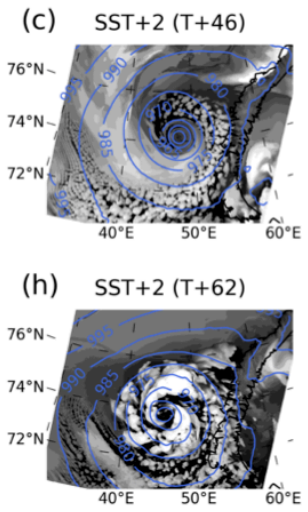
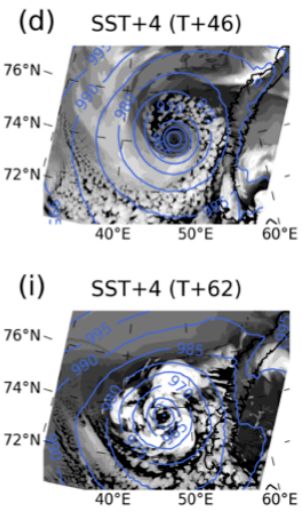
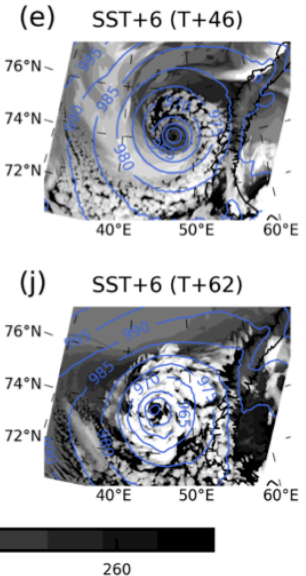

Figure 2. Simulated brightness temperatures for the indicated model runs at two times: (a)-(e) at $T+46$, i.e. 10:00 UTC on 19 December, corresponding to Figure 1(b); and (f)-(j) at T+62, i.e. 02:00 UTC on 20 December, corresponding to Figure 1(c). Simulated SLP contours are shown in blue with an interval of 5 $\mathrm{hPa}$.

It is difficult to compare simulated wind speed with QuikSCAT satellite-derived wind products. The data is provided in gridded form, but each 'snapshot' is a composite made up of several satellite passes. This is a 
This is a preprint. Please download the full article from the Quarterly Journal's web site.

potential source of inconsistency. We therefore show the two-dimensional QuikSCAT data along with the wind speed from the model simulations in Figure 3, with the forecast hour of the simulated wind speeds in the lower panels corresponding roughly to the mean capture times in the top panels. Figures 3(a) and 3(d) show that CTRL produced weaker winds than those indicated by QuikSCAT in the evening of 18 December, at $\mathrm{T}+33$. The structure of the system seems to be quite well reproduced, although the simulated PL is located too far to the north. One day later, at T+57, the QuikSCAT imagery in Figure 3(b) indicates that the system had developed a more circular shape. This is also true of the simulated PL shown in Figure 3(e). By this time the simulated wind speeds were still weaker than the QuikSCAT ones, but less so than one day earlier. The simulated PL was still too far to the north. At midnight on 20 December, just three hours after the previous time shown and two hours before the satellite image in Figure 1(c) was taken, QuikSCAT indicates that the wind speeds to the south-west of the PL had weakened (Figure 3(c)), and the PL itself still appeared to be circular in shape. These features are also found in the CTRL simulation shown in Figure 3(f). In summary, taking the potential inconsistencies of the QuikSCAT data into account (see discussion in the next section), the simulated PL corresponds quite well with what happened in reality. At the very least, it corresponds well enough for our purposes, which is not primarily to accurately reproduce the PL, but to quantify the effects of perturbing the SSTs.
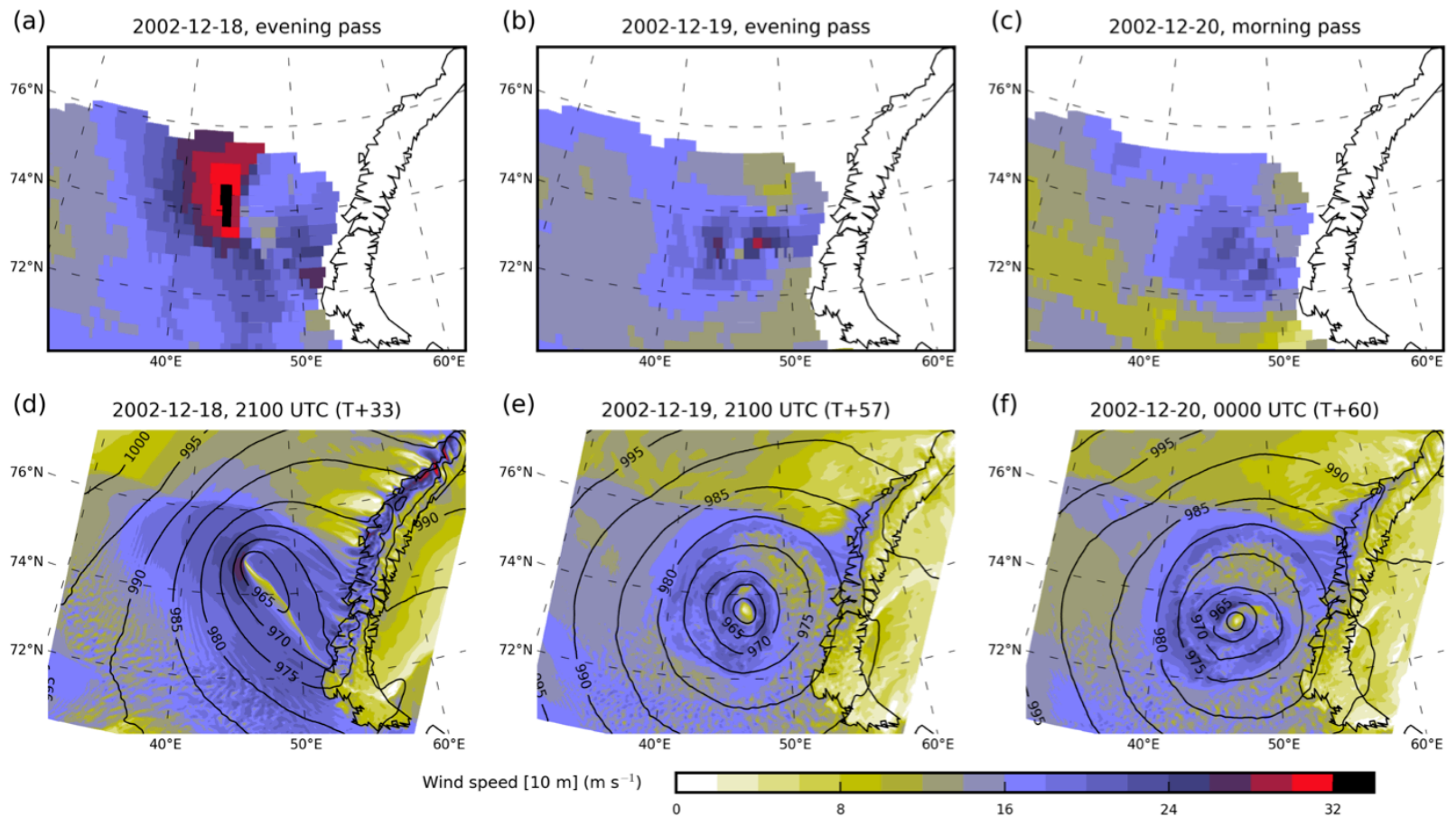

Figure 3. Simulated vs. satellite-derived wind speeds. In (a), the two-dimensional QuikSCAT wind speed is shown for the evening pass on $18^{\text {th }}$ December 2002. The images used were taken at about 2100 UTC on average, and the simulated wind speed for this time is shown in (d). Corresponding QuikSCAT/model pairs are shown in (b) and (e) for 2100 UTC on the $19^{\text {th }}$, and in (c) and (f) for 0000 UTC on the $20^{\text {th }}$. All the panels adhere to the same colour scheme, and the bottom panels also show contoured simulated $\mathrm{SLP}$ in $\mathrm{hPa}$.

We now present time series of the evolution of some key variables in the simulations in Figure 4, for which we will discuss the control run first. Figure 4(a) shows the tracks of the PLs as represented by the location of the SLP minima. The black circles show that the PL in CTRL moved over a gradually cooler sea surface (SSTs are shown with gray contours), and according to the reanalysis boundary data its development occurred over SSTs of $0-2{ }^{\circ} \mathrm{C}$. Figures $1-3$ indicated that the track in CTRL was a reasonable reproduction of the actual PL track until the control run PL made landfall just after $\mathrm{T}+80$. We do not know just when the actual PL made landfall. The latest available AVHRR image is from 09:54 UTC on 20 December (corresponding to T+70), and by then 
This is a preprint. Please download the full article from the Quarterly Journal's web site.

a closed cloud structure - presumably the low centre - was located quite close to the coast of Novaya Zemlya (not shown)

(a)

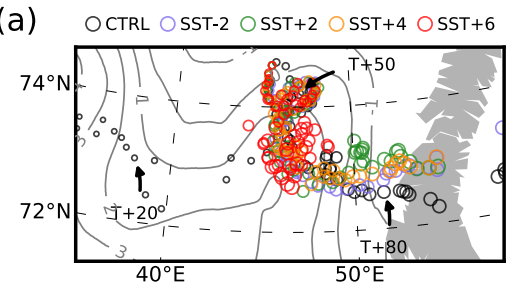

(d)

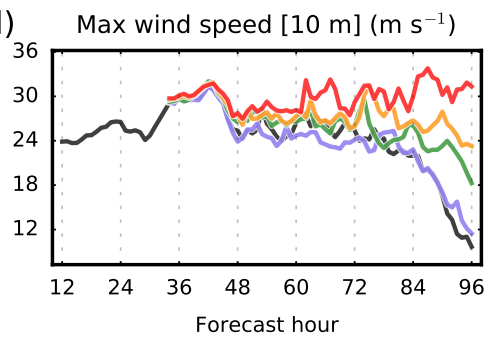

(g)

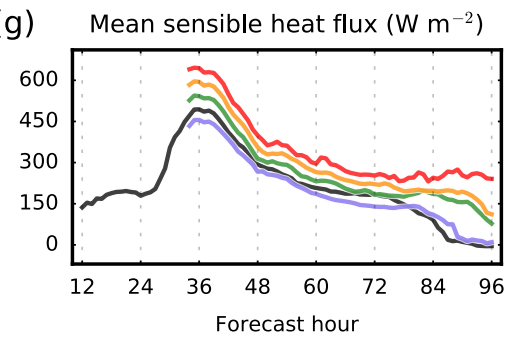

(b)

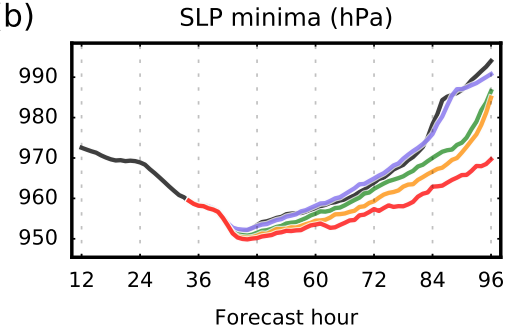

(e)

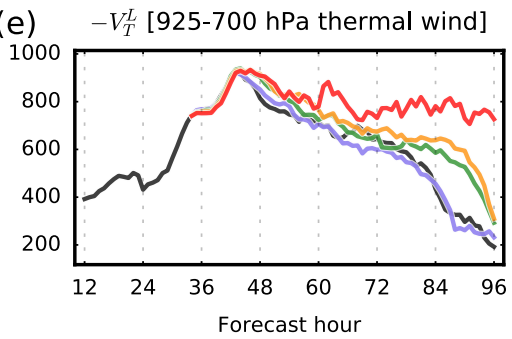

(h)

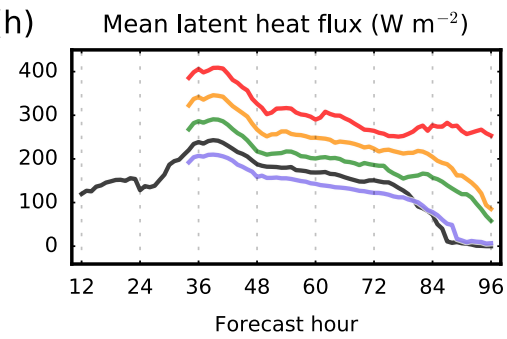

(c) Kinetic energy $[925-700 \mathrm{hPa}]\left(\mathrm{J} \mathrm{m} \mathrm{m}^{-3}\right)$

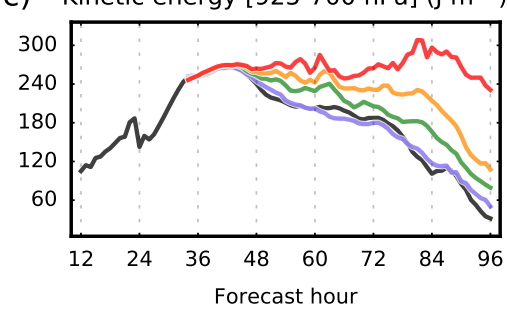

(f) Mean shear $[925-700 \mathrm{hPa}]\left(\mathrm{s}^{-1}\right)$

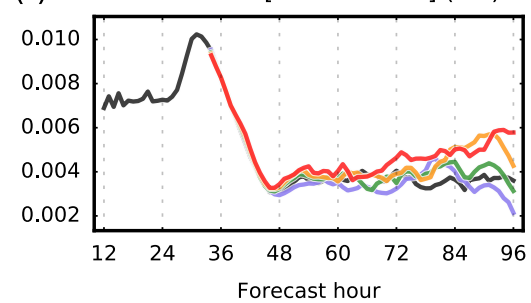

(i)

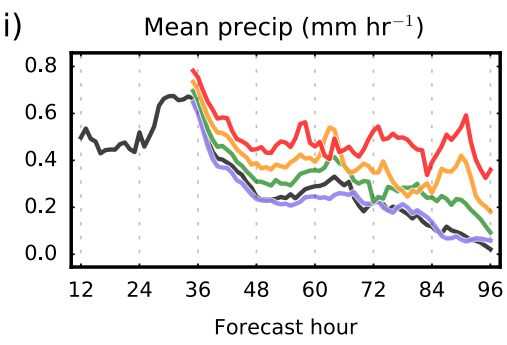

Figure 4. Evolutions of the simulated polar lows. (a) Hourly locations of SLP minima for the three simulations, with the width of the circles increasing with the forecast hour and the SSTs at the start of CTRL shown in ${ }^{\circ} \mathrm{C}$ with dashed curves. (b) SLP minima inside the model domain; (c) Mean kinetic energy between 925 and $700 \mathrm{hPa}$ for a circular region $r$ within $200 \mathrm{~km}$ from the surface low centre; (d) maximum wind speed inside $r$; (e) Hart's warm core indicator $-\mathrm{V}_{T}^{L}$ for $r$; (f) the mean vertical wind shear inside $r$; the mean sensible $(\mathrm{g})$ and latent $(\mathrm{h})$ heat fluxes inside $r$; and (i) the mean precipitation rate inside $r$. The colours in (b)-(i) follow the scheme described in the title of (a).

In the remaining panels of Figure 4, the black curves show the evolutions of the metrics described earlier in the control run. Figure 4(b) shows that the lowest SLP in CTRL occurred at 06:00 UTC on 19 December (T+42), as in Føre et al. (2012). The low-level kinetic energy shown in Figure 4(c), the maximum 10-metre wind speed in Figure 4(d), and the warm core indicator in Figure 4(e) also peaked around this time for CTRL. The mean vertical wind shear shown in Figure 4(f) indicates that the PL in CTRL became occluded around T+36, after which the wind shear declined rapidly and the PL entered its mature, post-baroclinic phase. The largest mean sensible heat fluxes in CTRL occurred just before $\mathrm{T}+36$ (Figure $4(\mathrm{~g})$ ), coinciding in time with the maximum cold air advection off the sea ice edge, while the largest mean latent heat fluxes in CTRL occurred around $\mathrm{T}+42$ (Figure 4(h)). The mean precipitation around the low, a useful indicator of latent heat release, peaked just before $\mathrm{T}+36$ and was lower in the mature phase, as shown in Figure 4(i).

The mechanisms for the development and maintenance of the PL in CTRL can be outlined as follows. The system had a warm core at $\mathrm{T}+42$ (Figure $4(\mathrm{e})$ ) and strong winds associated with the large local temperature gradients near the core (Figure 4(d)). Warm air rose above a back-bent front (Shapiro and Keyser, 1990) in the region to the west and south-west of the low centre, and created the cloud band in the satellite images in Figures 1(a)-(b). Differential latent heating above the front led to a sharper gradient between the warm and cold air, strengthening the already strong winds on the cold side. In the mature phase after $\mathrm{T}+42$ until the PL made landfall 
This is a preprint. Please download the full article from the Quarterly Journal's web site.

the wind speeds stayed moderately high (Figure 4(d)) and the warm core structure was largely maintained (Figure 4(e)), but the pressure increased gradually (Figure 4(b)). There was a slight temporary re-intensification after $\mathrm{T}+60$ (e.g. Figure 4(c)) consistent with the development of a dense cloud structure to the east and north of the PL centre seen in Figure 1(c). It is possible that this formed when warm air from the south and west (heated by surface fluxes) rose above colder air masses. Latent heat release may also have contributed to the convection (Craig and Cho, 1988), and the strongest surface winds occurred under the 'hook' of the dense cloud, in the region with large local temperature gradients. The incipient dense clouds associated with this secondary intensification can be seen to the north-east of the low centre in Figure 2(f).

What were the effects of decreasing the SSTs by $2 \mathrm{~K}$ in the simulation? The SLP shown in Figure 4(b) and the kinetic energy shown in Figure 4(c) both indicate that the SST-2 PL was slightly weaker than the PL in CTRL during the mature phase. Kinetic energy is perhaps the most robust indicator of cyclone strength, as it accounts for average horizontal and vertical wind speeds at three levels. It is less prone to random fluctuations than the maximum 10-metre wind speed shown in Figure 4(d), which also indicates that the SST-2 PL was slightly weaker than the CTRL PL. The warm core structure of the PL, which broke down when surface fluxes were switched off in KBZ, was not distinguishably affected by the lower SSTs (Figure 4(e)), nor was the vertical shear (Figure 4(f)), indicating that the underlying mechanisms were the same as in CTRL. The lower surface fluxes in SST-2 relative to CTRL shown in Figures 4(g) and 4(h) are consistent with the slight weakening of the PL.

What happened after the SSTs were artificially increased at T+39? The SST +2 PL, illustrated with green curves in Figure 4, maintained slightly higher energy than the PL in CTRL (Figure 4(c)) and re-intensified briefly around $\mathrm{T}+72$, producing high wind speeds (Figure 4(d)). As in CTRL, although slightly later, this was also due to the development of a dense convective cloud (not shown). The SST +4 PL (orange curves) also went through a similar re-development, with higher kinetic energy than the SST +2 PL (Figure 4(c)) and stronger wind speeds (Figure 4(d)). With higher SSTs, higher evaporation rates and heat loss to the atmosphere occurred, and the apparently roughly linear relationships between increasing SSTs and both latent heat fluxes (Figure 4(h)) and precipitation (Figure 4(i)) suggest that latent heat release was an important factor in regulating the levels of kinetic energy (Figure 4(c)). It was only when the SSTs were increased by $6 \mathrm{~K}$ that the kinetic energy of the system was sustained at the same level as at the baroclinic peak and even increased somewhat, as shown by the red curve in Figure 4(c), even though the SLP continued to increase (Figure 4(b)). The maximum wind speed was consistently around $30 \mathrm{~m} \mathrm{~s}^{-1}$ (Figure 4(d)). There is no clear indication of a change in the underlying mechanisms for the strong winds during the mature phase; the warm core structure appears to have been sustained to a larger degree than in the other runs (Figure 4(e)). The main reason for the higher energy appears to have been the enhanced fluxes (Figures 4(g)-(h)) and latent heat release (Figure 4(i)). The high fluxes partly occurred because the PL remained over warm water longer than the PLs in the other simulations, as shown by the red circles in Figure 4(a).

While the time series approach in Figure 4 provides a useful overview, some information is lost in the process. We therefore also present two-dimensional horizontal and vertical snapshots. The differences between the SST2 and SST +6 runs are illustrated with plots of near-surface wind speed and temperature and surface heat fluxes in Figure 5, and vertical cross sections are shown in Figure 6 (above the purple lines in Figure 5). We chose to focus on $\mathrm{T}+69$, as the two PLs were quite similar in structure at that time, despite 30 hours having passed since the SSTs were modified. The strongest wind speeds occurred below cold intrusions, which created very large local temperature gradients where they encountered the warm air masses associated with the core of the PL. This is especially evident to the south and northwest of the low in the SST +6 simulation (see Figure 5(b) for wind speed and Figure 5(d) for temperature). Figures 5(e) and 5(f) show that the largest sensible heat fluxes occurred just off the ice edge and in regions with high wind speed, while the largest latent heat fluxes were found to the south and west of the PL, as shown in Figures 5(g) and 5(h). Naturally, the fluxes were substantially higher in SST+6 than in SST -2 .

Figure 6 shows vertical cross sections passing through the surface low centres along the purple lines shown in Figure 5, also at $\mathrm{T}+69$. The highest wind speed occurred where the local temperature differences were greatest, as the thermal wind equation dictates. This led to strong winds along the edges of the warm cores, as shown by the black contours above the first tick marks to the left and right of the low centre in both panels of Figure 6 . In addition, several low-level wind speed maxima are evident. These were associated with cold air intruding into 
This is a preprint. Please download the full article from the Quarterly Journal's web site.

warmer air masses, as illustrated by the darker blue colours near the strongest wind speeds. These bands of strong winds were also clear in Figures 5(a)-(d).

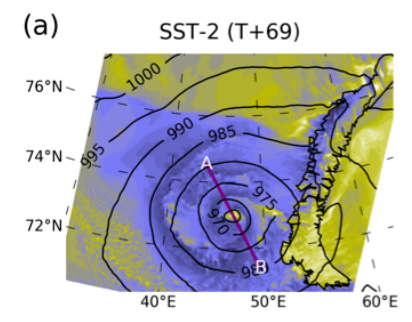

Wind speed $[10 \mathrm{~m}]\left(\mathrm{m} \mathrm{s}^{-1}\right)$

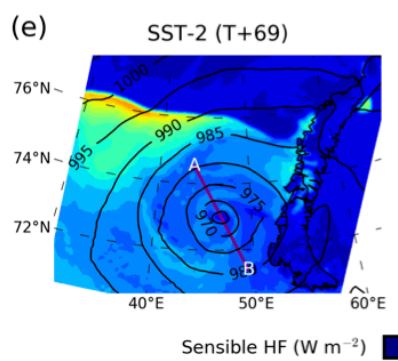

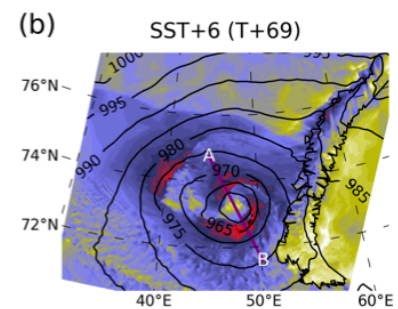
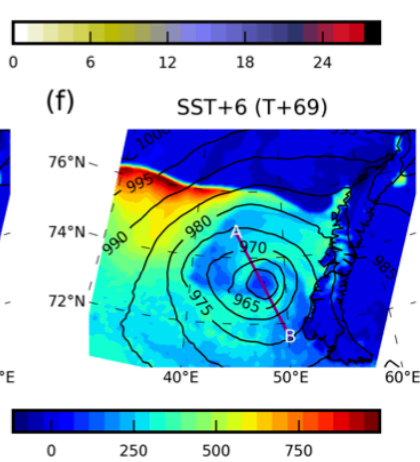

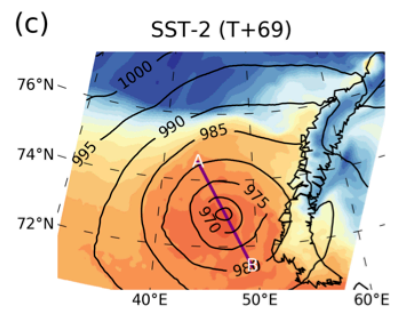

Temperature [Model level 1$]\left({ }^{\circ} \mathrm{C}\right)$

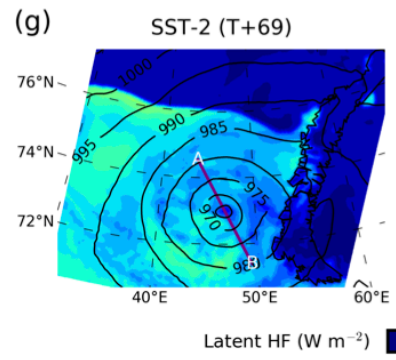

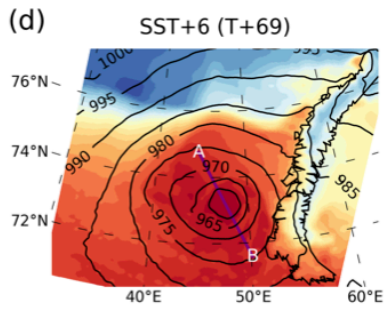
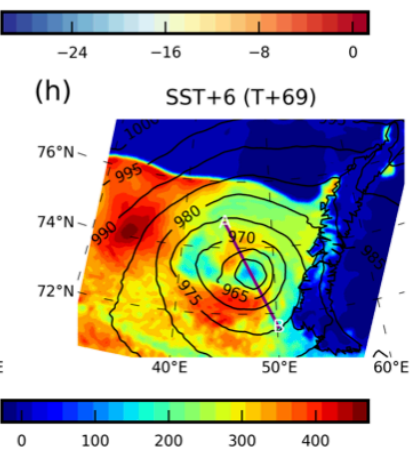

Figure 5. The SST-2 and SST+6 PLs at T+69. (a)-(b) Wind speed at 10 metres; (c)-(d) temperature at the lowest model level; (e)-(f) sensible heat flux; and $(g)-(h)$ latent heat flux. In all the panels, SLP is shown with a contour interval of $5 \mathrm{hPa}$, and the extents of the vertical cross sections in Figure 6 are marked with purple lines.

(a)

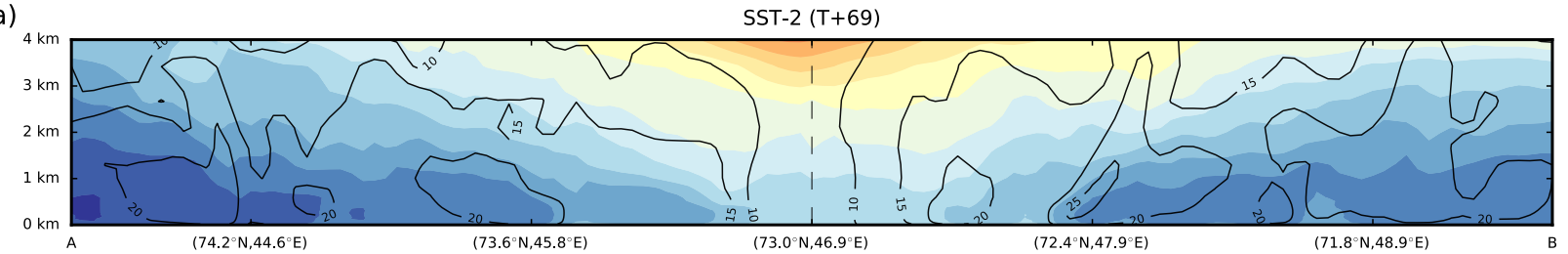

(b)

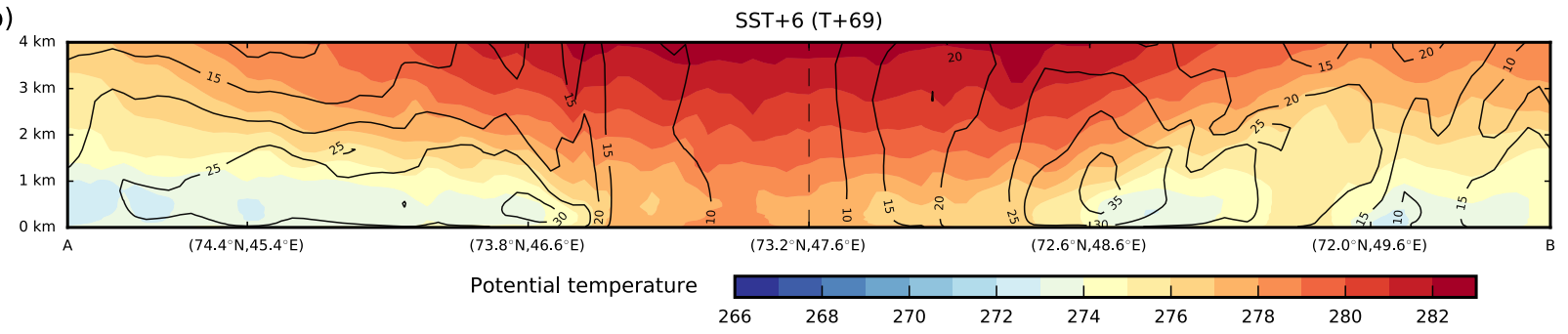

Figure 6. Vertical cross sections of the SST-2 and SST+6 PLs at T+69. The filled contours show potential temperature in $\mathrm{K}$ and the black contours show wind speed in $\mathrm{m} \mathrm{s}^{-1}$ with an interval of $5 \mathrm{~m} \mathrm{~s}^{-1}$. The horizontal extents from point A to point B for each model run are shown in Figure 5 . The sections were selected to intersect both the grid point with the lowest SLP and the grid point with the highest wind speed vertically. The distance from A to B in each case was about $400 \mathrm{~km}$.

It is obvious from Figure 6(b) that the increased heat fluxes from the ocean had heated up the air masses in a thick layer in SST +6 , probably mainly through advection and latent heating, but how did this affect the warm core structure? The potential temperature anomalies with respect to the mean along the A-B section, computed for each model level, are shown for both model runs in Figure 7. The warm core was slightly wider in SST +6 
This is a preprint. Please download the full article from the Quarterly Journal's web site.

than in SST-2, and the temperature gradients along the boundaries of the warm core were greater, especially near the surface. These increased gradients, and not a fundamental change in the PL's structure, were likely the main driver of the high wind speeds in SST +6 .

(a)

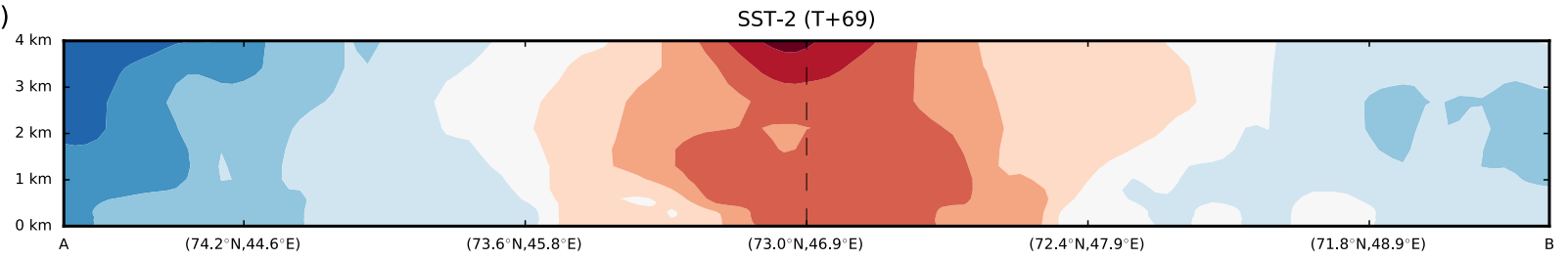

(b)

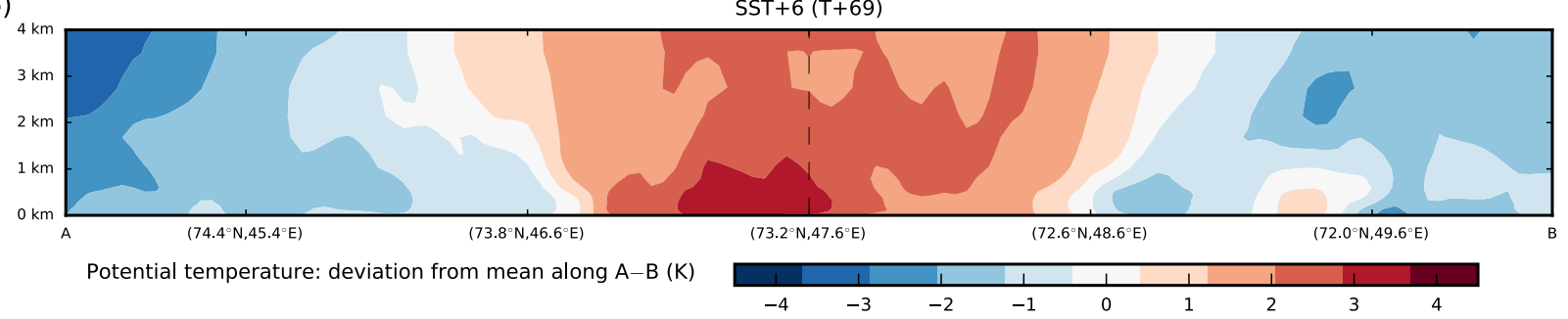

Figure 7. Vertical cross sections of potential temperature anomalies with respect to the model level mean along the transect from $\mathrm{A}$ to $\mathrm{B}$.

\section{Discussion}

There are some caveats that must be discussed. First, as in KBZ the model appears to have underestimated the strength of the PL in the baroclinicity-driven intensification phase in the control run, even when dissipative heating was parameterized. Such an underestimation would have led to smaller surface fluxes in the model simulations than in reality during the intensification phase, and this would also have affected the remainder of the PL's life cycle. The evidence of the underestimation is, however, somewhat uncertain, in that it rests solely on QuikSCAT imagery. This data product is problematic in that it is provided in gridded form and consists of composites of numerous satellite passes. In addition, the accuracy of the QuikSCAT data for very high wind speeds is unclear, as episodes with very high winds are under-represented in the data sets that were used for calibrating the retrieval algorithms (Hoffman and Leidner, 2005). The uncertainty in comparing the polar low intensity with what actually happened in reality highlights the need for improved observations and modelling of surface fluxes in cold-air outbreaks. This task was undertaken by projects like the Greenland Flow Distortion Experiment (Renfrew et al., 2008) and IPY-THORPEX (Kristjánsson et al., 2011), but there still remains much important work to be done.

Second, the use of nudging deprives the PL of a certain amount of freedom in its development. It is possible that an experiment with SSTs increased from the beginning, and with no nudging applied, would have produced a system with more hurricane-like characteristics. But then it would have been difficult to compare the development with the actual PL, as it would probably have moved away from the region in which the PL was located.

Third, it must be emphasised that the sudden SST changes in the model runs are unrealistic. In the future the atmosphere is projected to warm more quickly than the sea surface. This difference is estimated to be about $2 \mathrm{~K}$ following medium emissions scenarios (Kolstad and Bracegirdle, 2008). One possibility for future work would be to perform case studies such as this with a pseudo global warming approach (Schär et al., 1996), in which air temperatures as well as SSTs are increased, using changes from one or several climate model projections. But this is not without its technical challenges, such as the need to increase the geopotential height and the specific humidity to keep the atmosphere in balance and possibly also artificially moving the sea ice edge further north. As a consequence, this approach would require a specific focused study.

Fourth, it is not certain that the boundary layer in the model handled the large SST changes applied here in a physically consistent manner. Yet, the simulated brightness temperatures 7 hours after the SST changes, shown in Figures 2(a)-(e), do not appear to contain conspicuous features. 
This is a preprint. Please download the full article from the Quarterly Journal's web site.

Bearing these caveats in mind, a number of interesting findings can be extracted from our experiments. According to our model results, substantial and unrealistic increases in SST on the order of $6 \mathrm{~K}$ would have been required for the PL to exhibit significant further intensification by air-sea interaction in its mature phase. This is consistent with idealised studies that indicate SSTs of around 6-7 K are necessary to produce hurricane-force wind speeds (Emanuel and Rotunno, 1989; Yanase and Niino, 2005, 2007). Furthermore, it is intriguing that the changes induced by modifying the SSTs in our experiments appeared to be roughly linear. For even further increases in SST we would expect to see less linear responses in accordance with the Clausius-Clapeyron relation. A hint of non-linearity is observed in the SST+6 experiment.

Our results also suggest that a change in relative air-sea temperature difference of $2 \mathrm{~K}$ alone would not have had a major impact on the persistence and intensity of intense polar lows in their mature phase (the PL studied here was one of the most intense polar lows to have been investigated). Using climate model data downscaled to a grid spacing of $50 \mathrm{~km}$, Zahn and von Storch (2010) found that the frequency of North-East Atlantic polar lows was expected to decrease in the future, but they did not investigate whether the intensity of the most extreme polar lows would change. (Indeed, they could not have, as their model was run with a coarse grid spacing.) To study this with a convection-permitting model such as the one used here, perhaps by simulating a few cases with favourable conditions for strong polar lows, would be a worthwhile undertaking. Such an investigation could potentially clear up some of the uncertainty of how polar lows will behave in the future and how they would impact human activity in the Arctic.

It is possible that factors other than the vertical air-sea difference, such as a retreating sea ice edge, may be of importance in the future. As polar lows only form over open water, it is likely that the geographical area prone to polar low development will become larger in the future (Kolstad and Bracegirdle, 2008; Zabolotskikh et al., 2016), as there will be more open water. Large rates of sea ice retreat have already been observed in the northern and eastern parts of the Barents Sea (Årthun et al., 2012; Smedsrud et al., 2013), and further retreat is expected in this century (Sandø et al., 2014; Semenov et al., 2015). This retreat may potentially lead to an increased frequency of polar lows along the Northern Sea Route (Liu and Kronbak, 2010).

Another environmental factor that will probably change in the future is horizontal temperature gradients in the air and/or the ocean. However, climate models currently exhibit large errors in their representation of the sea ice edge in the Barents Sea (Holland et al., 2010). This means that the projected changes in horizontal temperature gradients are unfortunately quite unrealistic. It is to be hoped that future generations of climate models yield better representations of the Barents Sea ice edge and thereby more believable projections for the future.

\section{Acknowledgments}

The authors would like to thank two anonymous reviewers for their comments, which led to an improved paper. We also thank the vast community that has developed and continues to maintain the WRF model, as well as the ECMWF for providing the ERA-Interim reanalysis data. EWK was partly funded by the Norwegian Research Council through the Hordaklim (grant 245403) and R3 (grant 255397) projects.

\section{References}

Albright MD, Reed RJ, Ovens DW. 1995. Origin and structure of a numerically simulated polar low over Hudson Bay. Tellus. 47A: 834-848.

Beljaars ACM. 1995. The parametrization of surface fluxes in large-scale models under free convection. $Q$. $J$. R. Meteorol. Soc. 121: 255-270.

Bister M, Emanuel KA. 1998. Dissipative heating and hurricane intensity. Meteorology and Atmospheric Physics. 65: 233-240.

Blechschmidt AM, Bakan S, Grassl H. 2009. Large-scale atmospheric circulation patterns during polar low events over the Nordic seas. J. Geophys. Res. 114.

Bracegirdle TJ, Gray SL. 2009. The dynamics of a polar low assessed using potential vorticity inversion. $Q$. J. R. Meteorol. Soc. 135: 880-893.

Businger S. 1985. The synoptic climatology of polar low outbreaks. Tellus. 37A: 419-432. 
This is a preprint. Please download the full article from the Quarterly Journal's web site.

Claud C, Heinemann G, Raustein E, McMurdie L. 2004. Polar low le Cygne: Satellite observations and numerical simulations. Q. J. R. Meteorol. Soc. 130: 1075-1102.

Craig G, Cho H-R. 1988. Cumulus Heating and CISK in the Extratropical Atmosphere. Part I: Polar Lows and Comma Clouds. J. Atmos. Sci. 45: 2622-2640.

Craig GC, Gray SL. 1996. CISK or WISHE as the mechanism for tropical cyclone intensification. J. Atmos. Sci. 53: 3528-3540.

Dee DP, Uppala SM, Simmons AJ, Berrisford P, Poli P, Kobayashi S, Andrae U, Balmaseda MA, Balsamo G, Bauer P, Bechtold P, Beljaars ACM, van de Berg L, Bidlot J, Bormann N, Delsol C, Dragani R, Fuentes M, Geer AJ, Haimberger L, Healy SB, Hersbach H, Hólm EV, Isaksen L, Kållberg P, Köhler M, Matricardi M, McNally AP, Monge-Sanz BM, Morcrette JJ, Park BK, Peubey C, de Rosnay P, Tavolato C, Thépaut JN, Vitart F. 2011. The ERA-Interim reanalysis: Configuration and performance of the data assimilation system. Q. J. R. Meteorol. Soc. 137: 553-597.

Emanuel KA, Rotunno R. 1989. Polar lows as arctic hurricanes. Tellus. 41A: 1-17.

Ese T, Kanestrøm I, Pedersen K. 1988. Climatology of polar lows over the Norwegian and Barents Seas. Tellus. 40A: 248-255.

Evans JL, Hart RE. 2003. Objective Indicators of the Life Cycle Evolution of Extratropical Transition for Atlantic Tropical Cyclones. Mon. Weather Rev. 131: 909-925.

Føre I, Kristjánsson JE, Kolstad EW, Bracegirdle TJ, Saetra Ø, Røsting B. 2012. A ‘hurricane-like'polar low fuelled by sensible heat flux: high-resolution numerical simulations. Q. J. R. Meteorol. Soc. 138: 13081324.

Garratt JE, 1994: The Atmospheric Boundary Layer. Cambridge Atmospheric and Space Science Series, Cambridge University Press, 316 pp.

Green BW, Zhang F. 2013. Impacts of Air-Sea Flux Parameterizations on the Intensity and Structure of Tropical Cyclones. Mon. Weather Rev. 141: 2308-2324.

Grønås S, Kvamstø NG. 1995. Numerical simulations of the synoptic conditions and development of Arctic outbreak polar lows. Tellus. 47A: 797-814.

Hoffman RN, Leidner SM. 2005. An Introduction to the Near-Real-Time QuikSCAT Data. Weather Forecast. 20: 476-493.

Holland M, Serreze M, Stroeve J. 2010. The sea ice mass budget of the Arctic and its future change as simulated by coupled climate models. Clim. Dyn. 34: 185-200.

Jin Y, Thompson WT, Wang S, Liou C-S. 2007. A Numerical Study of the Effect of Dissipative Heating on Tropical Cyclone Intensity. Weather Forecast. 22: 950-966.

Kolstad EW, Bracegirdle TJ. 2008. Marine cold-air outbreaks in the future: an assessment of IPCC AR4 model results for the Northern Hemisphere. Clim. Dyn. 30: 871-885.

Kolstad EW. 2011. A global climatology of favourable conditions for polar lows. Q. J. R. Meteorol. Soc. 137: $1749-1761$.

Kolstad EW, Bracegirdle TJ, Zahn M. 2016. Re-examining the roles of surface heat flux and latent heat release in a 'hurricane-like' polar low over the Barents Sea. J. Geophys. Res. Atmos. 121: 7853-7867.

Kristjánsson JE, Barstad I, Aspelien T, Føre I, Godøy Ø, Hov Ø, Irvine E, Iversen T, Kolstad EW, Nordeng TE. 2011. The Norwegian IPY-THORPEX: Polar lows and Arctic fronts during the 2008 Andøya campaign. Bull. Am. Meteorol. Soc. 92: 1443-1466.

Liu M, Kronbak J. 2010. The potential economic viability of using the Northern Sea Route (NSR) as an alternative route between Asia and Europe. Journal of Transport Geography. 18: 434-444.

Mailhot J, Hanley D, Bilodeau B, Hertzman O. 1996. A numerical case study of a polar low in the Labrador Sea. Tellus. 48A: $383-402$.

Mansfield DA. 1974. Polar lows: The development of baroclinic disturbances in cold air outbreaks. Q. J. R. Meteorol. Soc. 100: 541-554.

Montgomery MT, Farrell BF. 1992. Polar Low Dynamics. J. Atmos. Sci. 49: 2484-2505.

Nakanishi M, Niino H. 2009. Development of an Improved Turbulence Closure Model for the Atmospheric Boundary Layer. J. Meteorol. Soc. Jpn. 87: 895-912. 
This is a preprint. Please download the full article from the Quarterly Journal's web site.

Nordeng TE. 1990. A model-based diagnostic study of the development and maintenance mechanism of two polar lows. Tellus. 42A: 92-108.

Nordeng TE, Rasmussen E. 1992. A most beautiful polar low. A case study of a polar low development in the Bear Island region. Tellus. 44A: 81-99.

Rasmussen E. 1979. The polar low as an extratropical CISK disturbance. Q. J. R. Meteorol. Soc. 105: 531-549.

Rasmussen EA, Turner J, 2003: Polar Lows: Mesoscale Weather Systems in the Polar Regions. Cambridge University Press.

Renfrew IA, Petersen GN, Outten S, Sproson D, Moore GWK, Hay C, Ohigashi T, Zhang S, Kristjánsson JE, Føre I, Ólafsson H, Gray SL, Irvine EA, Bovis K, Brown PRA, Swinbank R, Haine T, Lawrence A, Pickart RS, Shapiro M, Woolley A. 2008. The Greenland Flow Distortion Experiment. Bull. Am. Meteorol. Soc. 89: 1307-1324.

Sandø AB, Melsom A, Budgell WP. 2014. Downscaling IPCC control run and future scenario with focus on the Barents Sea. Ocean Dynamics. 64: 927-949.

Schär C, Frei C, Lüthi D, Davies HC. 1996. Surrogate climate-change scenarios for regional climate models. Geophys. Res. Lett. 23: 669-672.

Semenov VA, Martin T, Behrens LK, Latif M. 2015. Arctic sea ice area in CMIP3 and CMIP5 climate model ensembles - variability and change. The Cryosphere Discuss. 9: 1077-1131.

Shapiro M, Fedor L, Hampel T. 1987. Research aircraft measurements of a polar low over the Norwegian Sea. Tellus. 39A: 272-306.

Shapiro MA, Keyser DA, 1990: Fronts, jet streams, and the tropopause. Extratropical Cyclones: The Erik Palmén Memorial Volume, C. W. Newton and E. O. Holopainen, Eds., Amer. Meteor. Soc., 167-191.

Shimada U, Wada A, Yamazaki K, Kitabatake N. 2014. Roles of an upper-level cold vortex and low-level baroclinicity in the development of polar lows over the Sea of Japan. Tellus. 66A: 24694.

Skamarock WC, Klemp JB. 2008. A time-split nonhydrostatic atmospheric model for weather research and forecasting applications. Journal of Computational Physics. 227: 3465-3485.

Smedsrud LH, Esau I, Ingvaldsen RB, Eldevik T, Haugan PM, Li C, Lien VS, Olsen A, Omar AM, Otterå OH, Risebrobakken B, Sandø AB, Semenov VA, Sorokina SA. 2013. The role of the Barents Sea in the Arctic climate system. Rev. Geophys. 51: 415-449.

von Storch H, Langenberg H, Feser F. 2000. A Spectral Nudging Technique for Dynamical Downscaling Purposes. Mon. Weather Rev. 128: 3664-3673.

Yanase W, Niino H. 2005. Effects of baroclinicity on the cloud pattern and structure of polar lows: A highresolution numerical experiment. Geophys. Res. Lett. 32: L02806.

Yanase W, Niino H. 2007. Dependence of polar low development on baroclinicity and physical processes: An idealized high-resolution numerical experiment. J. Atmos. Sci. 64: 3044-3067.

Zabolotskikh EV, Gurvich IA, Chapron B. 2016. New areas of polar lows over the Arctic as a result of the decrease in sea ice extent. Izvestiya, Atmospheric and Oceanic Physics. 51: 1021-1033.

Zahn M, von Storch H. 2010. Decreased frequency of North Atlantic polar lows associated with future climate warming. Nature. 467: 309-312.

Årthun M, Eldevik T, Smedsrud LH, Skagseth Ø, Ingvaldsen RB. 2012. Quantifying the influence of Atlantic heat on Barents sea ice variability and retreat. J. Clim. 25: 4736-4743. 